\title{
Article \\ Bleomycin for Percutaneous Sclerotherapy of Venous and Lymphatic Malformations: A Retrospective Study of Safety, Efficacy and Mid-Term Outcomes in 26 Patients
}

\author{
Franck Nevesny ${ }^{1}$, Olivier Chevallier ${ }^{1}{ }^{\mathbb{D}}$, Nicolas Falvo ${ }^{1}$, Kévin Guillen $^{1}$, Alexandre Malakhia ${ }^{1}$, \\ Julie Pellegrinelli ${ }^{1}$, Pierre-Olivier Comby ${ }^{2}(0)$, Bertille Bonniaud ${ }^{3}$, Marco Midulla ${ }^{1}$ and Romaric Loffroy ${ }^{1, *} *$ \\ 1 Image-Guided Therapy Center, ImViA Laboratory-EA 7535, Department of Vascular and Interventional \\ Radiology, François-Mitterrand University Hospital, 14 Rue Paul Gaffarel, BP 77908, 21079 Dijon, France; \\ brothersfs@icloud.com (F.N.); olivier.chevallier@chu-dijon.fr (O.C.); nicolas.falvo@chu-dijon.fr (N.F.); \\ kguillen@hotmail.fr (K.G.); alexander.malakhia@chu-dijon.fr (A.M.); julie.pellegrinelli@chu-dijon.fr (J.P.); \\ marco.midulla@chu-dijon.fr (M.M.) \\ 2 Department of Neuroradiology and Emergency Radiology, François-Mitterrand University Hospital, \\ 14 Rue Paul Gaffarel, BP 77908, 21079 Dijon, France; pierre-olivier.comby@chu-dijon.fr \\ 3 Department of Dermatology and Genetics of Developmental Anomalies, UMR Inserm 1231, \\ François-Mitterrand University Hospital, 14 Rue Paul Gaffarel, BP 77908, 21079 Dijon, France; \\ bertille.bonniaud@chu-dijon.fr \\ check for \\ * Correspondence: romaric.loffroy@chu-dijon.fr; Tel.: +33-380-293-677
} updates

Citation: Nevesny, F.; Chevallier, O.; Falvo, N.; Guillen, K.; Malakhia, A.; Pellegrinelli, J.; Comby, P.-O.; Bonniaud, B.; Midulla, M.; Loffroy, R. Bleomycin for Percutaneous Sclerotherapy of Venous and Lymphatic Malformations: A Retrospective Study of Safety, Efficacy and Mid-Term Outcomes in 26 Patients. J. Clin. Med. 2021, 10, 1302. https://doi.org/10.3390/jcm10061302

Academic Editors: Süleyman Ergün and Olivier Morel

Received: 26 January 2021

Accepted: 18 March 2021

Published: 22 March 2021

Publisher's Note: MDPI stays neutral with regard to jurisdictional claims in published maps and institutional affiliations.

Copyright: () 2021 by the authors. Licensee MDPI, Basel, Switzerland. This article is an open access article distributed under the terms and conditions of the Creative Commons Attribution (CC BY) license (https:// creativecommons.org/licenses/by/ $4.0 /)$.

\begin{abstract}
Percutaneous sclerotherapy is used to treat venous and lymphatic vascular malformations, which can cause significant discomfort and/or disfigurement. The purpose of this study is to describe the bleomycin sclerotherapy technique and to evaluate its clinical and radiological efficacy and safety. We retrospectively identified consecutive patients with venous malformations (VMs) and lymphatic malformations (LMs) who underwent bleomycin sclerotherapy in 2011-2020 at our institution. We collected the clinical and radiological success rates, complications and recurrences separately in the VM and LM groups. We identified 26 patients, 15 with VMs and 11 with LMs. The significant volume reductions obtained were $45 \%$ in the VM group and $76 \%$ in the LM group $(p=0.003$ and $p=0.009$, respectively). Significant reductions in discomfort/pain and in cosmetic disfigurement were obtained in both groups. An overall improvement was reported by $69 \%$ and $82 \%$ of patients in the VM and LM groups, respectively. No major complications occurred during the mean follow-up of $51 \pm 34$ months in the VM group and $29 \pm 18$ months in the LM group. A recurrence developed within 2 years in $23 \%$ of patients. Bleomycin is clinically and radiologically effective for the treatment of venous and lymphatic malformations, with a high level of patient safety.
\end{abstract}

Keywords: venous malformations; lymphatic malformations; percutaneous sclerotherapy; bleomycin; patient-reported outcomes

\section{Introduction}

Venous and lymphatic malformations rare congenital defects resulting from abnormalities in vascular system development during the embryonic period. They are classified as low-flow vascular malformations [1]. They should not be confused with vascular tumours, such as haemangiomas, which are characterised by endothelial hyperplasia [2].

Venous malformations (VMs) are the most common, with an incidence of approximately 1 per 10,000 births, while lymphatic malformations (LMs) have an incidence of approximately 1 per 16,000 births [3]. These malformations enlarge with the growth of the child and may be diagnosed later on in life. VMs and LMs can cause discomfort and disfigurement, particularly when located near the surface of the skin and in the head and neck region. LMs are found on the proximal part of the neck in nearly $75 \%$ of cases $[4,5]$. Thus, the adverse effect on quality of life can be substantial. 
No strong treatment recommendations have been issued to date regarding which therapy or sclerosing agent should be used as first-line treatment in clinical practice. Surgical excision is not the first-line treatment because it more often leads to complications (haemorrhage, scarring and complications due to general anaesthesia) than other treatment methods. In recent years, percutaneous sclerotherapy has shown many advantages over surgical treatment, making it the preferred technique for first-line treatment [6]. Many sclerosing agents are available on the market, but there is no consensus regarding which is best [7]. The choice of the sclerosing agent is made on a case-by-case basis depending on the size and type of lesion and on its location. Ethanol is the most commonly used sclerosing agent and produces excellent results, although it also has the highest complication rate [8]. Bleomycin is a sclerosing agent with one of the lowest complication rates. Adverse events have been both minimal and transient [9]. However, it may increase the risk of skin hyperpigmentation and ulceration if injected too superficially under the skin. Bleomycin is a cytostatic antineoplastic agent that acts on the mechanistic target of rapamycin (mTOR) pathway. It induces an endothelial-to-mesenchymal transition that enhances its scleroembolic effect [10]. The cumulative lifetime dose of bleomycin should not exceed $400 \mathrm{mg}$ or $5 \mathrm{mg} / \mathrm{kg}$ to limit the risk of pulmonary fibrosis [11,12]. Because of this dose limitation, bleomycin should be used with caution to allow the treatment of VMs and LMs while minimising the total dose.

The objective of this study was to assess the clinical and radiological efficacy and safety of bleomycin sclerotherapy in 26 patients with VMs or LMs treated over a 9-year period.

\section{Materials and Methods}

\subsection{Study Population}

All bleomycin sclerotherapy procedures performed at our institution over the 9-year period from 2011 to 2020 were identified by searching the hospital's electronic database. Institutional review board was not required for this study due to its retrospective nature, but our ethics committee approved the study. For this single-centre cohort study, informed patient consent was waived in compliance with French legislation on retrospective studies of anonymized data. Patients treated with other sclerosing agents for VMs or LMs were excluded.

\subsection{Percutaneous Procedure}

Before the procedure, blood cell and platelet counts were measured, and simple coagulation studies were performed. No further examination, especially of lung function, was performed given the extreme rarity of lung toxicity of bleomycin at low doses.

The procedure was performed under local anaesthesia in 17 (65\%) patients and under general anaesthesia in $9(45 \%)$ patients. Reasons for general anaesthesia were young age (6 patients younger than 8 years), poor patient cooperation and anticipated technical challenges due to location of the malformation at the head or neck. Access to the lesion was obtained using an 18- to 25-gauge needle, at one to five sites; ultrasound guidance was used in $12(46 \%)$ patients. An iodinated contrast agent was then injected to observe the filling of the malformation under fluoroscopy. If there was evidence of extravasation, the access site was abandoned. The injectable solution was prepared by diluting $15 \mathrm{mg}$ of bleomycin in about $20 \mathrm{~mL}$ of $9 \% \mathrm{NaCl}$. The sclerosing agent was injected then slowly and carefully into the malformation under fluoroscopic guidance without contrast agent. Indeed, the malformation was already enhanced by previous contrast injection and washed with the sclerosing agent alone. The mean procedure time was less than $15 \mathrm{~min}$.

Each patient received an injection of $0.5 \mathrm{mg} / \mathrm{kg}$ of corticosteroids (Methylprednisolone ${ }^{\circledR}$ Mylan; Mylan S.A.S, Saint-Priest, France) during the scleroembolisation procedure and was prescribed paracetamol-tramadol tablets (Ixprim ${ }^{\circledR}$; Grünenthal, Aix-la-Chapelle, Germany) to be taken orally for 7 days after the procedure. 


\subsection{Data Collection and Follow-Up}

For each patient, the following data were collected from the electronic medical record: age, sex, location of the lesion, symptoms, volume $(\mathrm{mL})$ of the lesion before and after the end of the treatment, amount $(\mathrm{mL})$ of bleomycin injected, number of bleomycin injections and cumulative bleomycin dose.

We collected the peri-procedural complications, i.e., complications occurring within 30 days after the procedure and divided them into major and minor complications according to the Society of Interventional Radiology (SIR) classification [13]. Minor complications required no treatment or resolved within $24 \mathrm{~h}$ with symptomatic drugs. Major complications required treatment for more than $24 \mathrm{~h}$ or were more severe or irreversible.

To collect patient-reported outcomes, each patient was contacted by telephone in October 2020 and asked to complete a simple, standardized questionnaire. Patients completed a questionnaire evaluating disease symptoms and treatment satisfaction. Furthermore, the long-term outcomes of Bleomycin sclerotherapy were investigated in terms of patientperceived changes in health. Pain/discomfort before and after treatment was evaluated using a numerical rating visual analogue scale ranging from 0 (no pain) to 10 (extremely painful). Patients also rated the extent of perceived change in cosmetic appearance on a health insurance scale ranging from 1 (very mild) to 7 (very significant). Finally, overall patient satisfaction with the treatment results was assessed on a 5-level semantic scale, ranging from strongly improved to markedly worsened.

Treatment endpoint was defined as final volume reduction of more than $50 \%$ and/or clinical improvement of at least three clinical categories (pain/discomfort and cosmetic appearance) and/or two overall satisfaction categories. As long as the treatment was effective, it was continued until disappearance of the lesion. Recurrence was defined as any clinically significant increase in lesion volume.

A follow-up visit with magnetic resonance imaging (MRI) was scheduled 3 to 6 months after the treatment session.

\subsection{Statistical Analysis}

Descriptive statistics and parameters, such as frequencies and percentages, were used and provided in order to accurately describe our experience regarding the sclerotherapy procedure with bleomycin. Values are presented as number (\%), mean $\pm \mathrm{SD}$ or median (range).

In each of the two groups, the non-parametric Wilcoxon signed-rank test was used to compare the values at baseline and at last follow-up for lesion size (as measured objectively by MRI) and for pain/discomfort and change in cosmetic appearance (as assessed by the patient on the questionnaire). Differences between the two groups were compared the non-parametric Kruskal-Wallis test. Values of $P$ below 0.05 were taken to indicate statistically significant differences.

\section{Results}

\subsection{Patients and Malformations}

We identified 26 patients treated by bleomycin sclerotherapy for VMs or LMs at our centre from 2011 to June 2020. During the same period, 162 patients were treated with other sclerosing agents for vascular malformations, mainly venous and small malformations. Among the 26 patients, 15 (57\%) had VMs and 11 (43\%) had LMs. Table 1 reports their main features. Mean follow-up was $51 \pm 34$ months (range: 12-110) in the VM group and $29 \pm 18$ months (range: 12-60) in the LM group. 
Table 1. Characteristics of the 26 patients and sclerotherapy procedures.

\begin{tabular}{|c|c|c|}
\hline Clinical Data & VM & LM \\
\hline $\mathrm{n}$ & 15 & 11 \\
\hline Age (years) & $30.8 \pm 18.6(8-59)$ & $23.3 \pm 16.2(1-43)$ \\
\hline \multicolumn{3}{|l|}{ Sex } \\
\hline Male & $6(40)$ & $6(54.5)$ \\
\hline Female & $9(60)$ & $5(45.5)$ \\
\hline \multicolumn{3}{|l|}{ Location } \\
\hline Head and neck & $10(66.7)$ & $5(45.5)$ \\
\hline Extremity & $4(26.7)$ & $2(18.2)$ \\
\hline Trunk & $1(6.6)$ & $4(26.7)$ \\
\hline \multicolumn{3}{|l|}{ Previous treatment } \\
\hline Aetoxisclerol sclerotherapy & $5(33.3)$ & $0(0)$ \\
\hline Surgery & $0(0)$ & $0(0)$ \\
\hline Laser & $0(0)$ & $0(0)$ \\
\hline \multicolumn{3}{|l|}{ Additional treatment } \\
\hline Aetoxisclerol sclerotherapy & $3(20)$ & $2(18.2)$ \\
\hline Ethanol & $2(13.3)$ & $0(0)$ \\
\hline Surgery & $0(0)$ & $1(9.1)$ \\
\hline \multicolumn{3}{|l|}{ Primary symptom } \\
\hline Pain & $8(53.3)$ & $4(26.7)$ \\
\hline Swelling & $15(100)$ & $11(100)$ \\
\hline Bleeding & $1(6.7)$ & $1(9.1)$ \\
\hline Treatment sessions & $2.1 \pm 1.5(1-6)$ & $1.3 \pm 0.7(1-3)$ \\
\hline Sclerotherapy volume per patient (mL) & $30.0 \pm 22.0(15-60)$ & $20.0 \pm 10.5(10-45)$ \\
\hline
\end{tabular}

$\overline{\mathrm{VM}}$, venous malformation; LM, lymphatic malformation; $\mathrm{n}$, number. Values are as $\mathrm{n}$ (\%) or mean $\pm \mathrm{SD}$ (range).

Magnetic resonance imaging (MRI) was performed in 24 (92\%) patients before the procedure to confirm the diagnosis. Each malformation was measured on a T2-weighted turbo spin-echo (TSE) or short TI inversion recovery (STIR) MRI sequence by volumetric analysis via a $3 \mathrm{D}$ multi-modality processing platform to ensure measurement reproducibility. Of the remaining two patients, one underwent ultrasonography and the other had no imaging study. The effect of treatment in this patient was then assessed visually.

Five $(19 \%)$ patients, all in the VM group, had had sclerotherapy of the same lesion using polidocanol (Aetoxisclerol ${ }^{\circledR} 2 \%$; Kreussler Pharma, Paris, France) as the sclerosing agent. All these sclerotherapy procedures were performed more than 6 months before inclusion in our study.

Table 2 reports the mean lesion volume in both groups. Heterogeneity was considerable, with volumes ranging from 2 to $700 \mathrm{~mL}$ in the VM group and 7 to $4212 \mathrm{~mL}$ in the LM group. The volume differences explain the differences in the number of injections, with ranges from 1 to 6 in the VM group and 1 to 3 in the LM group. The decision to perform repeat bleomycin injections was based on the reduction in malformation volume and on the patient's overall clinical improvement as defined above. When several injections were required, the procedures were scheduled 5 to 6 weeks apart to minimise the risk of side effects. The cumulative bleomycin dose for all patients was $450 \mathrm{~mL}$ in the VM group and $220 \mathrm{~mL}$ in the LM group, respectively.

Eight $(30 \%)$ patients received additional treatment after the last bleomycin sclerotherapy procedure, five in the VM group and three in the LM group. Additional aetoxisclerol sclerotherapy sessions were provided to three VM-group patients and two LM-group patients. Ethanol was used in 1 patient in the VM group and surgery in 1 patient in the LM group. The volume of the different lesions secondary treated with other sclerosing agents was stable over time, with no significant reduction (less than 15\%), except in the patient treated surgically. 
Table 2. Radiological results, clinical outcomes and overall satisfaction.

\begin{tabular}{|c|c|c|c|}
\hline Variable & VM & $\mathbf{L M}$ & $p$ Value \\
\hline \multicolumn{4}{|l|}{ Lesion MRI volume (mL) } \\
\hline $\mathrm{n}$ & 11 & 10 & \\
\hline Pre-treatment volume & $37 / 142 \pm 242(3-645)$ & $41 / 545 \pm 1379(7-4212)$ & \\
\hline Posttreatment volume & $21 / 136 \pm 216(0.2-480)$ & $7 / 532 \pm 1487(0-4212)$ & \\
\hline Volume reduction & $45 \pm 27.8(2-97)$ & $83 \pm 39(0-100)$ & 0.340 \\
\hline$p$ value & 0.003 & 0.009 & \\
\hline Volume reduction $>50 \%$ & $7(64)$ & $8(80)$ & \\
\hline \multicolumn{4}{|l|}{ Pain/discomfort } \\
\hline $\mathrm{n}$ & 13 & 11 & \\
\hline Pre-treatment VAS & $6.0 \pm 1.6(4-8)$ & $7.6 \pm 2.5(0-10)$ & \\
\hline Posttreatment VAS & $3.2 \pm 2.1(0-7)$ & $1.9 \pm 2.1(0-6)$ & \\
\hline VAS reduction & $2.8 \pm 2.1(0-6)$ & $5.7 \pm 3.1(0-10)$ & 0.019 \\
\hline$p$ value & 0.002 & 0.004 & \\
\hline \multicolumn{4}{|l|}{ Cosmesis } \\
\hline $\mathrm{n}$ & 13 & 11 & \\
\hline Pre-treatment score & $4.5 \pm 2.3(1-7)$ & $5.0 \pm 1.9(2-7)$ & \\
\hline Posttreatment score & $3.4 \pm 2.2(1-6)$ & $1.7 \pm 1.0(1-3)$ & \\
\hline Score improvement & $1.1 \pm 1.5(0-5)$ & $3.3 \pm 2.3(0-6)$ & 0.017 \\
\hline$p$ value & 0.016 & 0.005 & \\
\hline \multicolumn{4}{|l|}{ Overall satisfaction } \\
\hline $\mathrm{n}$ & 13 & 11 & \\
\hline Markedly improved & $3(23.0)$ & $6(54.5)$ & \\
\hline Slightly improved & $6(46.2)$ & $3(27.3)$ & \\
\hline Markedly + slightly improved & $9(69.2)$ & $9(81.8)$ & 0.116 \\
\hline No change & $4(30.8)$ & $2(18.2)$ & \\
\hline Slightly worsened & $0(0)$ & $0(0)$ & \\
\hline Markedly worsened & $0(0)$ & $0(0)$ & \\
\hline
\end{tabular}

VM, venous malformation; LM, lymphatic malformation; MRI, magnetic resonance imaging; $\mathrm{mL}$, millilitres; VAS, visual analog scale; $\mathrm{n}$, number. Values are as $\mathrm{n}(\%)$ or median/mean $\pm \mathrm{SD}$ (range). Values of $p$ below 0.05 were taken to indicate statistically significant differences.

\subsection{Radiological Outcomes}

A final MRI scan was obtained in 21 (81\%) patients, 11 in the VM group and 10 in the LM group. Table 2 reports the volume reductions after the last bleomycin injection.

A significant reduction in lesion volume was observed in 17 patients $(17 / 21,82 \%)$ and the percentage reduction ranged from $2 \%$ to $97 \%$ in the VM group and $0 \%$ to $100 \%$ in the LM group (Figures 1 and 2). In the VM group, 3/11 patients (27\%) had a volume reduction greater than $70 \%$, five (45\%) had a reduction of $20 \%$ to $70 \%$ and three $(27 \%)$ had less than $20 \%$ of reduction. In the LM group, $8 / 10$ (80\%) patients had a reduction greater than $70 \%$, including three $(3 / 8,37 \%)$ with elimination of the malformation and two $(25 \%)$ patients had less than $20 \%$ of reduction. None of the patients experienced any growth of the malformation after treatment. In the five remaining patients with no final MRI, two of the VM group and one of the LM group were markedly improved with a malformation which almost clinically disappeared. No data were available for the two remaining patients.

\subsection{Patient-Reported Outcomes}

The clinical outcomes were assessed by a telephone interview in 24 (92\%) patients, 13 in the VM group and 11 in the LM group, in October, 2020. Each patient completed the standardised questionnaire described above. The two remaining patients had no telephone interview and no post-treatment MRI; they were considered as lost to follow-up. Table 2 reports the main findings. 


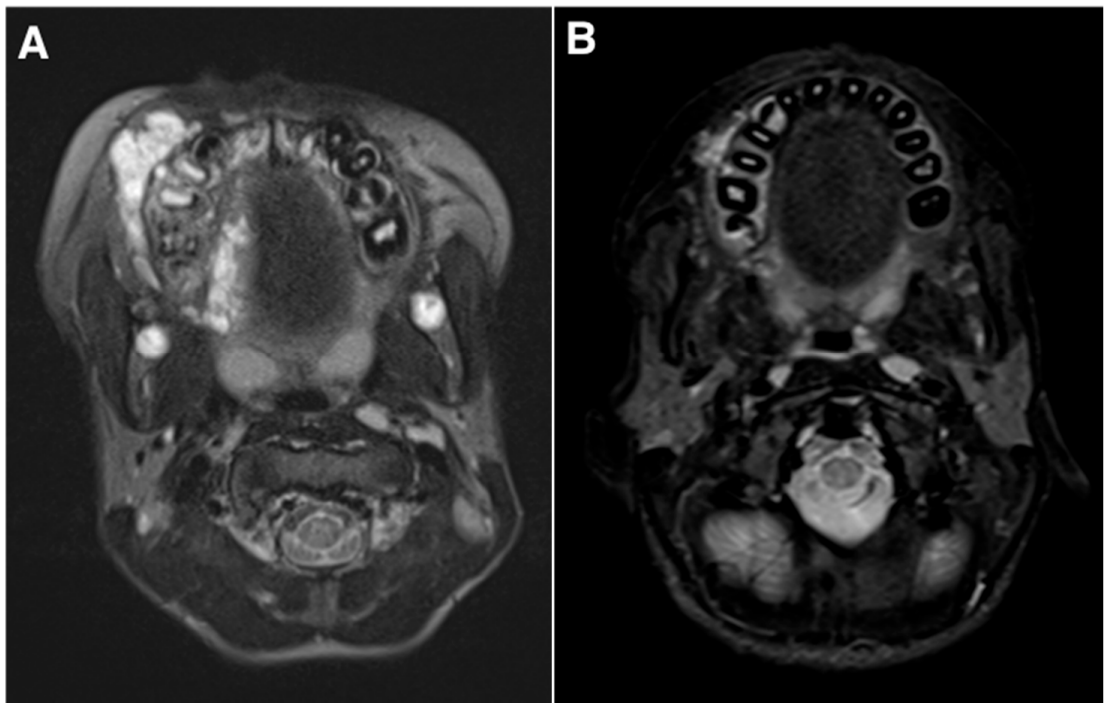

Figure 1. Images from a 32-year-old male with symptomatic venous malformation (VM). (A) pretreatment T2-weighted STIR magnetic resonance imaging (MRI) showing an extensive VM of the right cheek cantered on the upper jaw. (B) Post-treatment T2-weighted MRI after two sessions of bleomycin sclerotherapy showing significant volume reduction of the VM (about 70\%), with significant discomfort (visual analog scale, 2 versus 5 ), cosmesis score (2 versus 6) and overall satisfaction (markedly) improvement.

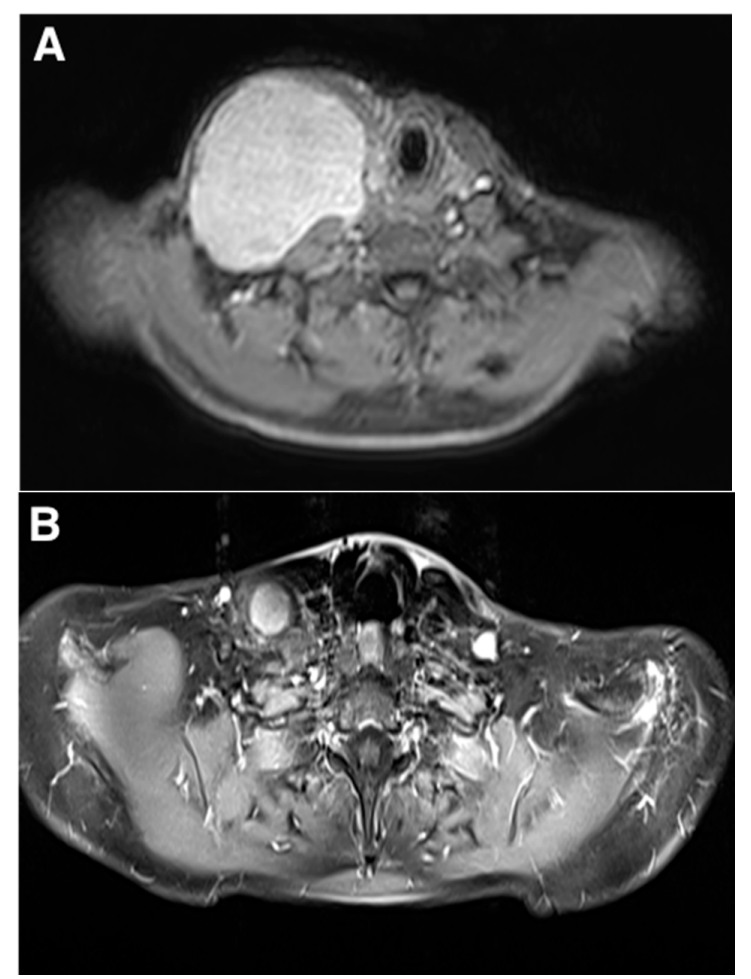

Figure 2. Images from a 39-year-old female with symptomatic lymphatic malformation (LM). (A) Pretreatment T1-weighted post-gadolinium magnetic resonance imaging (MRI) showing an extensive cystic lymphangioma of the right supraclavicular fossa and neck. (B) Post-treatment T1-weighted MRI post-gadolinium after two sessions of bleomycin sclerotherapy showing significant volume reduction of the LM (about $80 \%$ ) with significant discomfort (VAS, 1 versus 6), cosmesis score (1 versus 7) and overall satisfaction (markedly) improvement. 
On the pain/discomfort scale, eight (35\%) patients (three in the VM group and five in the LM group) had a reduction $\geq 5$ points compared to their baseline value, whereas three $(13 \%)$ patients showed no improvement in pain/discomfort. An improvement in pain/discomfort versus baseline was obtained in 11 (74\%) VM-group patients and nine (85\%) LM-group patients

Cosmesis was significantly improved in both groups (Table 2). The improvement in cosmesis on the 1-7 scale was greater than three points in seven (63\%) LM-group patients and $2(16 \%)$ VM-group patients. There was no improvement in cosmesis in six $(26 \%)$ patients, two in the VM group and four in the LM group.

Finally, of the 24 patients contacted, nine patients (37\%) including six in the LM group $(67 \%)$ and three in the VM group (23\%) reported that they were "markedly improved" by the treatment compared to their baseline condition, nine patients (37\%) reported being "slightly improved" (six in the VM group and 3 in the LM group) and six patients (25\%) reported no overall change compared to their baseline condition.

Although no statistics were performed regarding the correlation between radiological and clinical outcomes, $44 \%$ of the nine patients in whom the volume reduction by MRI was less than $50 \%$ reported pain/discomfort relief of three points or more on the numerical rating scale.

A total of 18 patients reported an overall improvement (from slight to marked), nine patients $(69 \%)$ in the VM group and nine patients $(82 \%)$ in the LM group.

No patients reported an overall worsening from baseline.

\subsection{Complications}

All procedures were technically successful. As shown in Table 3, no major complications occurred during follow-up. The injections were performed as outpatient procedures, under local anaesthesia in 17 patients and under general anaesthesia in nine patients. Hospital stay length was $1.3 \pm 0.6$ days (range: $1-3$ ) in the VM group and $1 \pm 0$ day (range: 1-1) in the LM group. In the VM group, one patient had a 3-day hospital stay due to swelling in the ear, nose and throat that required prolonged clinical monitoring.

Table 3. Complications and follow-up.

\begin{tabular}{ccc}
\hline Variable & VM & LM \\
\hline $\mathrm{n}$ & 15 & 11 \\
Major complications & $0(0)$ & $0(0)$ \\
Minor complications & $4(26.7)$ & $4(36.4)$ \\
Pain & $1(6.7)$ & $1(9.1)$ \\
Skin pigmentation & $1(6.7)$ & $1(9.1)$ \\
Swelling & $2(13.3)$ & $1(9.1)$ \\
Bleeding & $0(0)$ & $0(0)$ \\
Nausea & $0(0)$ & $0(0)$ \\
Fever & $0(0)$ & $0(0)$ \\
Local infection & $0(0)$ & $1(9.1)$ \\
Hospital stay (days) & $1.3 \pm 0.6(1-3)$ & $1.0 \pm 0.0(1-1)$ \\
Follow-up (months) & $\pm 14(12-120)$ & $29 \pm 18(12-60)$ \\
Recurrence & & $1(9.1)$ \\
At 6 months & $0(0)$ & $2(18.2)$ \\
At 24 months & $3(20)$ & $2(18.2)$ \\
At mean follow-up & $3(20)$ & (range).
\end{tabular}

Minor transient post-procedural complications occurred in eight (30\%) patients, four in each group. Among them, the most common were swelling, skin hyperpigmentation and pain ( $8 \%$ ). Infection of the puncture site occurred in one patient in the LM group and resolved with antibiotic therapy. 
In all, six $(23 \%)$ patients experienced recurrences. The recurrences were noted at six months in one LM-group patient and at 2 years in three VM-group and two LMgroup patients.

\subsection{Comparison of the Groups with Venous Versus Lymphatic Malformations}

The treatment responses were significantly better in the LM group than in the VM group, notably regarding the reduction in pain/discomfort (5.73 points versus 2.85 points, $p=0.019$ ) and the improvement in cosmesis (3.28 points versus 1.08 points, $p=0.016$ ). The reduction in lesion volume was also greater in the LM group than in the VM group (76\% versus $45 \%)$, although the difference was not significant $(p=0.34)$, perhaps due to the small sample size. The LM group required less bleomycin than did the VM group (mean dose per patient, $20 \pm 10 \mathrm{~mL}$ (range: $10-45$ ) versus $30 \pm 22 \mathrm{~mL}$ (range: 15-60)) and also had fewer injections (1.3 versus 2.1). No statistical test was performed for these parameters.

\section{Discussion}

In our study, one or more bleomycin injections proved effective in decreasing the volume of VMs and LMs. The volume decrease was greater for LMs than for VMs. Given the considerable variability in lesion size at baseline, the effect of the treatment was best expressed as the percentage of size reduction. The reduction was at least $50 \%$ for $64 \%$ of the VMs and $87 \%$ of the LMs. There were no major complications and minor complications were rare. Significant improvements were obtained regarding pain/discomfort, cosmesis and overall improvement in the patient-perceived changes in health and treatment satisfaction.

Venous and lymphatic malformations are rare congenital conditions whose causes and risk factors are largely unknown. They are generally present from birth and enlarge with age. Klippel-Trenaunay syndrome (KTS) is a rare congenital disease $(1 / 30,000$ births) characterized by a triad of cutaneous capillary malformations, varicose veins and hypertrophy of the bone and soft tissues [12]. In our cohort, 1 patient in the VM group had KTS.

Lesion volume is generally used to assess the efficacy of treatments for VMs and LMs. In most studies, a reduction of at least 50\% defined a good to excellent result and we used the same threshold. As shown in Table 4, our results were similar to those in the literature, with a greater than $50 \%$ volume reduction of about $82 \%$ of LMs versus $83 \%$ on average for 11 studies included in a meta-analysis [14]. Regarding the VM group, our results were worse than those in the literature, with a greater than $50 \%$ reduction in only $64 \%$ of patients compared to $84 \%$ on average in 10 published studies [14]. This result may be partially explained by the absence of MRI follow-up data for 2 VM-group patients who saw significant clinical improvements following the treatment and who would have had a good to excellent MRI result. Two more patients had no MRI at all.

However, it should be noted that lesion volume on MRI does not always correlate with symptomatic improvement [15], although most studies used volume reduction as the primary endpoint. We therefore included a questionnaire to assess patient-reported outcomes including pain/discomfort, cosmetic disfigurement and overall improvement in quality of life. Of note, four $(44 \%)$ of the nine patients in whom the volume reduction by MRI was less than $50 \%$ reported pain/discomfort relief of three points or more on the numerical rating scale. Only scant data are available on cosmesis or symptom-related quality of life, but a prospective study in 95 paediatric patients treated with bleomycin injections for haemangiomas and vascular malformations showed a $67 \%$ improvement in cosmesis [11], which is similar to our result.

Patients tended to perceive subtle changes rather than drastic improvements in their overall condition. Thus, only $37 \%$ of our patients reported a marked improvement in overall satisfaction. In contrast, in a study where the physicians evaluated the improvement, they found an excellent overall response for $87 \%$ of VMs and $84 \%$ of LMs [16]. This discrepancy underlines the importance of collecting patient-reported outcomes. Most of our patients had expectations that exceeded what can be realistically achieved. Complete long-term remissions are rare, recurrences are common and occur within a short time 
frame and several interventions are generally necessary over the patient's lifetime to alleviate the symptoms and improve cosmesis. The lifelong nature of venous and lymphatic malformations should be explained to the patients at the time of the diagnosis and feasible improvements should be described so that patients can adjust their expectations to reality.

None of our 26 patients experienced major complications and eight (30\%) had minor complications that resolved fully. A retrospective study of 55 patients with VMs reported comparable results, with minor complications in $10(18.2 \%)$ patients [17]. A meta-analysis of 27 studies (1325 patients) treated with bleomycin reported a total of 192 adverse events $(14 \%)$. The most common complications were swelling $(10 \%)$, fever $(4 \%)$ and wound infection (1\%). Transient hyperpigmentation occurred in $0.8 \%$ of cases [14].

Bleomycin was first used as an anti-tumour agent in the 1960s [16]. It was first used as a sclerosing agent in 1977 to treat cystic lymphangioma [18]. Bleomycin is associated with a risk of pulmonary fibrosis when given in large cumulative doses $(>400 \mathrm{mg}$ during the lifetime or a single $30 \mathrm{mg}$ dose). The risk is greatest in elderly patients, patients with kidney disease and patients with cancer undergoing systemic bleomycin therapy $[19,20]$. The mean cumulative intra-lesional dose in our study was $30 \pm 22 \mathrm{~mL}$ per patient in the VM group and $20 \pm 10 \mathrm{~mL}$ in the $\mathrm{LM}$ group, i.e., far lower than the doses associated with pulmonary fibrosis. We are aware of a single report of acute pulmonary toxicity after bleomycin sclerotherapy, in an 8-month-old infant who received an intra-lesional total dose of $7 \mathrm{mg}$ and recovered fully without developing pulmonary fibrosis [21]. No cases of lung toxicity occurred in our patients. Nevertheless, a larger cohort study with a longer follow-up may be necessary to assess the prevalence of this complication.

The efficacy of bleomycin also compares well with that of other commonly used sclerosing agents. Ethanol has long been recognized as the strongest sclerosing agent, with a remission rate ranging from $75 \%$ to $95 \%$ [11] and is widely used due to its availability, low cost and broad indications [22]. However, since 2016, several studies have shown that bleomycin is non-inferior to ethanol. In a meta-analysis, bleomycin provided similar volume reductions as did other sclerosing agents but with fewer complications (odds ratio, $0.1 ; 95 \%$ CI, 0.03-0.39) [14].

In addition, a recent meta-analysis of 32 studies included 1121 patients with venolymphatic malformations of the head and neck, treated with different sclerosing agents (bleomycin, pingyangmycin, ethanol and sodium tetradecyl sulphate sclerotherapy) [23]. Of the 1121 patients, bleomycin was used for 562 patients and pingyangmycin for 559 patients. A lesion reduction was found in $93.7 \%$ of patients with a mean number of sclerotherapy sessions per patient of 3.4 (range: 1-9). Minor complications occurred in $16.2 \%$ of patients while major complications occurred in only four $(1.1 \%)$ patients. Pingyangmycin sclerotherapy achieved subjective or objective lesion size reduction in $96.3 \%$ [23]. Another meta-analysis of nine retrospective cohort studies involving 132 patients suffering from orbital and periorbital veno-lymphatic malformations assessed results of sclerotherapy [24]. When LMs and VMs were treated with bleomycin, objective reduction was achieved for $78.5 \%$ and $100 \%$ of the patients, respectively. When LMs and VMs were treated with pingyangmycin, objective reduction was achieved for $96 \%$ et $100 \%$, respectively. Minor complications rate was less than $10 \%$ for pingyangmycin and around $26 \%$ with bleomycin. No major complications were reported with the use of pingyangmycin [24].

In practice, bleomycin sclerotherapy as the first choice in our study was at the discretion of the interventional radiologist. However, our main criteria for choosing between bleomycin and polidocanol as first line treatment was based on the lesion volume. In case of small lesions, polidocanol was preferred because of the risk of being not able to inject a sufficient volume of bleomycin. At the opposite, bleomycin was preferred in case of larger lesions because of the impossibility of injecting safely a large amount of polidocanol. Then, bleomycin was not used as first-line, but mainly dedicated to vascular malformations which were potentially contraindicated to polidocanol sclerotherapy. 
Table 4. Outcomes of bleomycin sclerotherapy for VM and LM in main series from the literature.

\begin{tabular}{|c|c|c|c|c|}
\hline Author, Year & $\begin{array}{c}\text { Definition of Good to } \\
\text { Excellent } \\
\text { Improvement }\end{array}$ & N Total & $\begin{array}{l}\text { N According to } \\
\text { Definition }\end{array}$ & $\begin{array}{l}\% \text { According to } \\
\text { Definition }\end{array}$ \\
\hline \multicolumn{5}{|l|}{ VM } \\
\hline Zhi et al., 2007 [25] & $>50 \%$ & 82 & 79 & 96 \\
\hline Chen et al., 2010 [26] & $>50 \%$ & 11 & 10 & 91 \\
\hline Sainsbury et al., 2011 [27] & $>60 \%$ & 42 & 38 & 90 \\
\hline Spence et al., 2011 [28] & $>50 \%$ & 17 & 15 & 88 \\
\hline Yue et al., 2013 [29] & $>50 \%$ & 12 & 11 & 92 \\
\hline Zhang et al., 2013 [10] & $>80 \%$ & 63 & 41 & 65 \\
\hline Bai et al., 2014 [30] & $>60 \%$ & 40 & 39 & 97 \\
\hline Jia et al., 2014 [31] & $>50 \%$ & 33 & 31 & 94 \\
\hline Mohan et al., 2014 [32] & $>50 \%$ & 27 & 24 & 89 \\
\hline Ul Haq et al., 2015 [33] & $>50 \%$ & 14 & 8 & 57 \\
\hline Songsaeng et al., 2015 [34] & $>75 \%$ & 16 & 12 & 75 \\
\hline Shigematsu et al., 2018 [35] & $>50 \%$ & 18 & 18 & 100 \\
\hline Sindel et al., 2018 [36] & $>50 \%$ & 20 & 17 & 85 \\
\hline Ahmad et al., 2019 [37] & $>75 \%$ & 35 & 16 & 45 \\
\hline Helal et al., 2019 [38] & $>60 \%$ & 30 & 30 & 100 \\
\hline Mean & - & 31 & 26 & 84 \\
\hline Our study & $>50 \%$ & 11 & 7 & 64 \\
\hline \multicolumn{5}{|l|}{ LM } \\
\hline Orford et al., 1995 [39] & $>50 \%$ & 16 & 14 & 88 \\
\hline Zulfiqar et al., 1999 [40] & $>50 \%$ & 11 & 8 & 73 \\
\hline Kim et al., 2004 [41] & $>50 \%$ & 10 & 6 & 60 \\
\hline Mathur et al., 2005 [42] & $>50 \%$ & 7 & 4 & 57 \\
\hline Rawat et al., 2006 [43] & $>50 \%$ & 19 & 16 & 84 \\
\hline Niramis et al., 2010 [44] & $>50 \%$ & 70 & 58 & 83 \\
\hline Rozman et al., 2011 [45] & $>50 \%$ & 24 & 20 & 83 \\
\hline Sandlas et al., 2011 [46] & $>50 \%$ & 10 & 9 & 90 \\
\hline Kumar et al., 2012 [47] & $>50 \%$ & 35 & 33 & 94 \\
\hline Erikci et al., 2013 [5] & $>50 \%$ & 14 & 12 & 86 \\
\hline Chaudry et al., 2014 [48] & $>90 \%$ & 31 & 12 & 38 \\
\hline Raichura et al., 2017 [49] & $>60 \%$ & 13 & 12 & 92 \\
\hline Porwal et al., 2018 [50] & $>50 \%$ & 8 & 8 & 100 \\
\hline Nuruddin et al., 2019 [51] & $>70 \%$ & 12 & 12 & 100 \\
\hline Mean & - & 21 & 18 & 82 \\
\hline Our study & $>50 \%$ & 10 & 8 & 80 \\
\hline
\end{tabular}

VM, venous malformation; LM, lymphatic malformation; N, number; \%, percentage.

Our study has the limitations inherent in the retrospective design. First, the sample size was small, reflecting the rarity of vascular malformations. Second, no subclassification of the type of VMs and LMs was performed given the small number of patients, preventing outcome assessment by malformation subtype. Third, the variability in lesion size made volumetric data analysis heterogeneous. To overcome this limitation, the effect of the treatment was best expressed by the median volume reduction in percentage. Fourth, five patients did not undergo a final MRI assessment. Fifth, the patient-reported outcomes were collected in October 2020, several months to several years after the end of the treatment, creating a risk of recall/memory bias. However, the vast majority of sclerotherapy procedures took place after 2015 and were performed in young patients (average age $<30$ years old). These patients were very involved in the course of their disease, having accurate knowledge of their symptoms and treatments. Furthermore, two patients did not complete the questionnaire. Finally, the questionnaire did not list all the symptoms experienced by the patients. 


\section{Conclusions}

Although our study included a limited number of patients, it suggests that percutaneous bleomycin is safe and effective for the treatment of VMs and LMs. The lesion size reduction was $50 \%$ or more for $64 \%$ of the VMs and $87 \%$ of the LMs. Most patients reported improvements in pain/discomfort and cosmesis, although only a minority felt markedly improved. The patient-reported outcomes did not consistently reflect the efficacy in terms of lesion size reduction. Finally, further research is needed to understand why bleomycin sclerotherapy was more effective in the LM group than in the VM group.

Author Contributions: Conceptualization, F.N. and R.L.; Methodology, O.C., N.F. and A.M.; Software, K.G.; Validation, O.C. and R.L.; Formal analysis, N.F., J.P. and M.M.; Investigation, F.N., O.C., P.-O.C., B.B. and R.L.; Resources, K.G.; Data curation, J.P.; Writing-original draft preparation, F.N., O.C., N.F., P.-O.C., M.M. and R.L.; Writing-review and editing, F.N., O.C., K.G., A.M., P.-O.C. and R.L.; Visualization, R.L.; Supervision, R.L.; Project administration, B.B.; Funding acquisition, B.B. All authors have read and agreed to the published version of the manuscript.

Funding: This research received no external funding.

Institutional Review Board Statement: Institutional review board was not required for this study due to its retrospective nature, but our ethics committee approved the study.

Informed Consent Statement: Patient consent was waived in compliance with French legislation on retrospective studies of anonymized data.

Data Availability Statement: The data presented in this study are available on request from the corresponding author. The data are not publicly available due to identity reasons.

Acknowledgments: Special thanks to the Pharmacy staff for their support.

Conflicts of Interest: The authors declare no conflict of interest.

\section{References}

1. Carqueja, I.M.; Sousa, J.; Mansilha, A. Vascular malformations: Classification, diagnosis and treatment. Int. Angiol. 2018, 37, 127-142.

2. Mulliken, J.B.; Glowacki, J. Hemangiomas and Vascular Malformations in Infants and Children. Plast. Reconstr. Surg. 1982, 69, 412-420. [CrossRef]

3. Legiehn, G.M.; Heran, M.K. Venous Malformations: Classification, Development, Diagnosis, and Interventional Radiologic Management. Radiol. Clin. N. Am. 2008, 46, 545-597. [CrossRef] [PubMed]

4. Colbert, S.D.; Seager, L.; Haider, F.; Evans, B.T.; Anand, R.; Brennan, P.A. Lymphatic malformations of the head and neck-Current concepts in management. Br. J. Oral Maxillofac. Surg. 2013, 51, 98-102. [CrossRef]

5. $\quad$ Erikçi, V.; Hoşgör, M.; Yıldız, M.; Örnek, Y.; Aksoy, N.; Okur, Ö.; Demircan, Y.; Genişol, İ. Intralesional bleomycin sclero-therapy in childhood lymphangioma. Turk. J. Pediatr. 2013, 55, 396-400. [PubMed]

6. Albanese, G.; Kondo, K.L. Pharmacology of Sclerotherapy. Semin. Interv. Radiol. 2010, 27, 391-399. [CrossRef] [PubMed]

7. Horbach, S.E.R.; Lokhorst, M.M.; Saeed, P.; Pontouraude, C.M.; Rothová, A.; Van Der Horst, C.M.A.M. Sclerotherapy for low-flow vascular malformations of the head and neck: A systematic review of sclerosing agents. J. Plast. Reconstr. Aesthetic Surg. 2016, 69, 295-304. [CrossRef]

8. Jin, Y.; Lin, X.; Li, W.; Hu, X.; Ma, G.; Wang, W. Sclerotherapy after embolization of draining vein: A safe treatment method for venous malformations. J. Vasc. Surg. 2008, 47, 1292-1299. [CrossRef] [PubMed]

9. Zhang, J.; Li, H.-B.; Zhou, S.-Y.; Chen, K.-S.; Niu, C.-Q.; Tan, X.-Y.; Jiang, Y.-Z.; Lin, Q.-Q. Comparison between absolute ethanol and bleomycin for the treatment of venous malformation in children. Exp. Ther. Med. 2013, 6, 305-309. [CrossRef]

10. Zhang, W.; Chen, G.; Ren, J.-G.; Zhao, Y.-F. Bleomycin induces endothelial mesenchymal transition through activation of mTOR pathway: A possible mechanism contributing to the sclerotherapy of venous malformations. Br. J. Pharmacol. 2013, 170, 1210-1220. [CrossRef] [PubMed]

11. Muir, T.; Kirsten, M.; Fourie, P.; Dippenaar, N.; Ionescu, G.O. Intralesional bleomycin injection (IBI) treatment for haemangiomas and congenital vascular malformations. Pediatr. Surg. Int. 2004, 19, 766-773. [CrossRef]

12. Samuel, M.; Spitz, L. Klippel-Trenaunay syndrome: Clinical features, complications and management in children. BJS 1995, 82 , 757-761. [CrossRef] [PubMed]

13. Sacks, D.; McClenny, T.E.; Cardella, J.F.; Lewis, C.A. Society of Interventional Radiology Clinical Practice Guidelines. J. Vasc. Interv. Radiol. 2003, 14, S199-S202. [CrossRef]

14. Horbach, S.E.R.; Rigter, I.M.; Smitt, J.H.S.; Reekers, J.A.; Spuls, P.I.; Van Der Horst, C.M.A.M. Intralesional Bleomycin Injections for Vascular Malformations. Plast. Reconstr. Surg. 2016, 137, 244-256. [CrossRef] [PubMed] 
15. Vogelzang, R.L.; Atassi, R.; Vouche, M.; Resnick, S.; Salem, R. Ethanol Embolotherapy of Vascular Malformations: Clinical Outcomes at a Single Center. J. Vasc. Interv. Radiol. 2014, 25, 206-213. [CrossRef] [PubMed]

16. Horbach, S.E.R.; Van De Ven, J.S.; Nieuwkerk, P.T.; Spuls, P.I.; Van Der Horst, C.M.A.M.; Reekers, J.A. Patient-Reported Outcomes of Bleomycin Sclerotherapy for Low-Flow Vascular Malformations and Predictors of Improvement. Cardiovasc. Interv. Radiol. 2018, 41, 1494-1504. [CrossRef]

17. Yang, X.; Chen, H.; Gu, H.; Jin, Y.; Hu, L.; Hua, C.; Wang, Y.; Sun, Y.; Yu, W.; Lin, X. Interim results of bleomycin-polidocanol foam sclerotherapy as a highly efficient technique for venous malformations. J. Vasc. Surg. Venous Lymphat. Disord. 2020, 8, 1066-1073. [CrossRef] [PubMed]

18. Luzzatto, C.; Midrio, P.; Tchaprassian, Z.; Guglielmi, M. Sclerosing treatment of lymphangiomas with OK-432. Arch. Dis. Child. 2000, 82, 316-318. [CrossRef]

19. Blum, R.H.; Carter, S.K.; Agre, K. A clinical review of bleomycin-A new antineoplastic agent. Cancer 1973, 31, 903-914. [CrossRef]

20. O'Sullivan, J.M.; Huddart, R.A.; Norman, A.R.; Nicholls, J.; Dearnaley, D.P.; Horwich, A. Predicting the risk of bleomycin lung toxicity in patients with germ-cell tumours. Ann. Oncol. 2003, 14, 91-96. [CrossRef] [PubMed]

21. Atwa, K.; Abuhasna, S.; Shihab, Z.; Hashaykeh, N.; Hasan, R. Acute pulmonary toxicity following intralesional administration of bleomycin for a lymphovenous malformation. Pediatr. Pulmonol. 2010, 45, 192-196. [CrossRef]

22. Lee, H.; Kim, T.; Kim, J.-M.; Kim, G.-W.; Ko, H.; Kim, B.-S.; Kim, M.-B.; Kim, H.-S. Percutaneous sclerotherapy using bleomycin for the treatment of vascular malformations. Int. J. Dermatol. 2017, 56, 1186-1191. [CrossRef] [PubMed]

23. Finitsis, S.; Faiz, K.; Linton, J.; Shankar, J.J.S. Bleomycin for head and neck venolymphatic malformations-A systematic review. Can. J. Neurol. Sci./J. Can. Sci. Neurol. 2020, 1-23. [CrossRef]

24. Faiz, K.; Finitsis, S.; Linton, J.; Shankar, J.J.S. Bleomycin for orbital and peri-orbital veno-lymphatic malformations-A systematic review. Interv. Neuroradiol. 2020, 1591019920972514. [CrossRef]

25. Zhi, K.; Wen, Y.; Li, L.; Ren, W. The role of intralesional Pingyangmycin in the treatment of venous malformation of facial and maxillary region. Int. J. Pediatr. Otorhinolaryngol. 2008, 72, 593-597. [CrossRef] [PubMed]

26. Chen, W.-L.; Huang, Z.-Q.; Zhang, D.-M.; Chai, Q. Percutaneous sclerotherapy of massive venous malformations of the face and neck using fibrin glue combined with OK-432 and pingyangmycin. Head Neck 2009, 32, 467-472. [CrossRef] [PubMed]

27. Sainsbury, D.C.G.; Kessell, G.; Fall, A.J.; Hampton, F.J.; Guhan, A.; Muir, T. Intralesional Bleomycin Injection Treatment for Vascular Birthmarks: A 5-Year Experience at a Single United Kingdom Unit. Plast. Reconstr. Surg. 2011, 127, 2031-2044. [CrossRef]

28. Spence, J.; Krings, T.; Terbrugge, K.G.; Agid, R. Percutaneous treatment of facial venous malformations: A matched comparison of alcohol and bleomycin sclerotherapy. Head Neck 2011, 33, 125-130. [CrossRef]

29. Yue, H.; Qian, J.; Elner, V.M.; Guo, J.; Yuan, Y.-F.; Zhang, R.; Ge, Q. Treatment of orbital vascular malformations with intralesional injection of pingyangmycin. Br. J. Ophthalmol. 2013, 97, 739-745. [CrossRef]

30. Bai, N.; Chen, Y.-Z.; Fu, Y.-J.; Wu, P.; Zhang, W.-N. A clinical study of pingyangmycin sclerotherapy for venous malformation: An evaluation of 281 consecutive patients. J. Clin. Pharm. Ther. 2014, 39, 521-526. [CrossRef] [PubMed]

31. Jia, R.; Xu, S.; Huang, X.; Song, X.; Pan, H.; Zhang, L.; He, F.; Lin, M.; Ge, S.; Fan, X. Pingyangmycin as First-Line Treatment for Low-Flow Orbital or Periorbital Venous Malformations. JAMA Ophthalmol. 2014, 132, 942-948. [CrossRef] [PubMed]

32. Mohan, A.T.; Adams, S.; Adams, K.; Hudson, D.A. Intralesional bleomycin injection in management of low flow vascular malformations in children. J. Plast. Surg. Hand Surg. 2014, 49, 116-120. [CrossRef]

33. Haq, F.U.; Mitchell, S.E.; Tekes, A.; Weiss, C.R. Bleomycin Foam Treatment of Venous Malformations: A Promising Agent for Effective Treatment with Minimal Swelling. J. Vasc. Interv. Radiol. 2015, 26, 1484-1493. [CrossRef]

34. Songsaeng, D.; Churojana, A.; Khumthong, R.; Mahiwan, L. Comparative outcomes for sclerotherapy of head and neck ve-nous vascular malformation between alcohol and bleomycin. J. Med. Assoc. Thai 2015, 98, 408-413. [PubMed]

35. Shigematsu, T.; Sorscher, M.; Dier, E.C.; Berenstein, A. Bleomycin sclerotherapy for eyelid venous malformations as an alternative to surgery or laser therapy. J. Neurointerv. Surg. 2018, 11, 57-61. [CrossRef] [PubMed]

36. Sindel, A.; Sayan, A.; Özgür, Ö.; Sindel, T.; Ilankovan, V. Percutaneous treatment of orofacial vascular malformations. Br. J. Oral Maxillofac. Surg. 2018, 56, 206-211. [CrossRef] [PubMed]

37. Ahmad, S. Efficacy of Percutaneous Sclerotherapy in Low Flow Venous Malformations-A Single Center Series. Neurointervention 2019, 14, 53-60. [CrossRef]

38. Helal, H.A.; Mahmoud, N.A. Effect of foam and liquid bleomycin in the management of venous malformations in head and neck region: A comparative study. J. Plast. Reconstr. Aesthetic Surg. 2020, 73, 90-97. [CrossRef] [PubMed]

39. Orford, J.; Barker, A.; Thonell, S.; King, P.; Murphy, J. Bleomycin therapy for cystic hygroma. J. Pediatr. Surg. 1995, 30, 1282-1287. [CrossRef]

40. Zulfiqar, M.A.; Zaleha, A.M.; Zakaria, Z.; Amin, T. The treatment of neck lymphangioma with intralesional injection of bleomycin. Med. J. Malays. 1999, 54, 478-481.

41. Kim, K.H.; Sung, M.-W.; Roh, J.-L.; Han, M.H. Sclerotherapy for Congenital Lesions in the Head and Neck. Otolaryngol. Neck Surg. 2004, 131, 307-316. [CrossRef]

42. Mathur, N.N.; Rana, I.; Bothra, R.; Dhawan, R.; Kathuria, G.; Pradhan, T. Bleomycin sclerotherapy in congenital lymphatic and vascular malformations of head and neck. Int. J. Pediatr. Otorhinolaryngol. 2005, 69, 75-80. [CrossRef] [PubMed]

43. Rawat, J.D.; Sinha, S.K.; Kanojia, R.P.; Wakhlu, A.; Kureel, S.N.; Tandon, R.K. Non surgical management of cystic lymphangioma. Indian J. Otolaryngol. Head Neck Surg. 2006, 58, 355-357. [CrossRef] 
44. Niramis, R.; Watanatittan, S.; Rattanasuwan, T. Treatment of Cystic Hygroma by Intralesional Bleomycin Injection: Experience in 70 Patients. Eur. J. Pediatr. Surg. 2010, 20, 178-182. [CrossRef] [PubMed]

45. Rozman, Z.; Thambidorai, R.R.; Zaleha, A.M.; Zakaria, Z.; Zulfiqar, M.A. Lymphangioma: Is intralesional bleomycin sclerotherapy effective? Biomed. Imaging Interv. J. 2011, 7, e18. [PubMed]

46. Sandlas, G.; Kothari, P.; Karkera, P.; Gupta, A. Bleomycin: A worthy alternative. Indian J. Plast. Surg. 2011, 44, 50-53. [CrossRef] [PubMed]

47. Gangopadhyay, A.N.; Kumar, V.; Kumar, P.; Pandey, A.; Gupta, D.K.; Shukla, R.C.; Sharma, S.P. Intralesional bleomycin in lymphangioma: An effective and safe non-operative modality of treatment. J. Cutan. Aesthetic Surg. 2012, 5, 133-136. [CrossRef] [PubMed]

48. Chaudry, G.; Guevara, C.J.; Rialon, K.L.; Kerr, C.; Mulliken, J.B.; Greene, A.K.; Fishman, S.J.; Boyer, D.; AlOmari, A.I. Safety and Efficacy of Bleomycin Sclerotherapy for Microcystic Lymphatic Malformation. Cardiovasc. Interv. Radiol. 2014, 37, $1476-1481$. [CrossRef]

49. Raichura, N.D.; Alam, S.; Noronha, V.O.; Mukherjee, B. A prospective study of the role of intralesional bleomycin in orbital lymphangioma. J. Am. Assoc. Pediatr. Ophthalmol. Strabismus 2017, 21, 146-151. [CrossRef]

50. Porwal, P.K.; Dubey, K.P.; Morey, A.; Singh, H.; Pooja, S.; Bose, A. Bleomycin Sclerotherapy in Lymphangiomas of Head and Neck: Prospective Study of 8 Cases. Indian J. Otolaryngol. Head Neck Surg. 2018, 70, 145-148. [CrossRef]

51. Nuruddin, M.; Roy, S.R.; Mudhar, H.S. Results of Intralesional Bleomycin Sclerotherapy for Treatment of Orbital Lymphangiomas at a Tertiary Eye Care Centre in Bangladesh. Ocul. Oncol. Pathol. 2019, 5, 412-417. [CrossRef] [PubMed] 